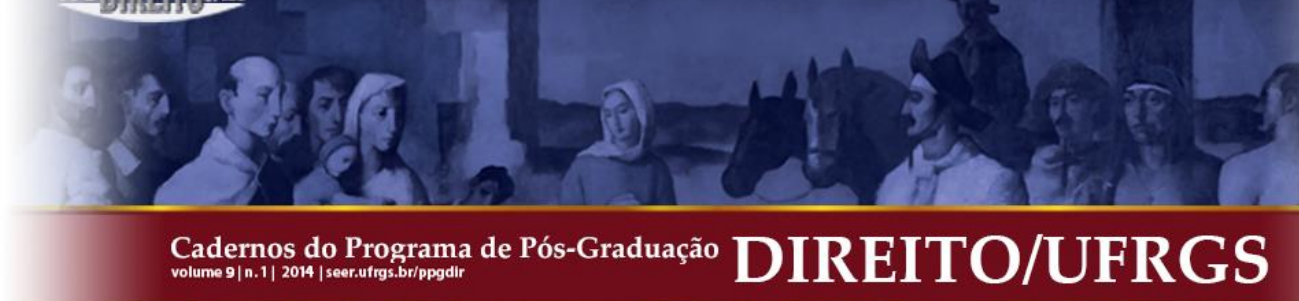

\title{
ALIENAÇÃO E CLANDESTINIDADE, OU O RUMO PERVERSO DA POLÍTICA
}

\author{
ALIENATION AND ILLEGALITY, OR THE PERVERSE ROUTE OF THE POLITICS
}

\section{Martonio Mont'Alverne Barreto Lima*}

\begin{abstract}
RESUMO: O texto investiga o conceito de alienação em Karl Marx, reanalisado por Friedrich Müller, a partir da perspectiva de Rousseau, Hegel e Marx. Se a alienação é uma categoria central do pensamento de Marx, na verdade, é este conceito já entendido por Rousseau, permanecendo atual nas sociedades de economia de mercado, especialmente aquelas que integram a chamada periferia do capitalismo. Nesse sentido, constata-se manifestações do fenômeno da alienação em sociedades como a brasileira, notadamente durante a experiência da chamada "crise política" de 2005/06 que se abateu sobre o governo do Presidente Lula. É aqui que se pode verificar, ainda, o aspecto perverso da alienação.
\end{abstract}

PAlaVRAS-CHAVE: Alienação; Capitalismo Periférico; Política Brasileira.

\begin{abstract}
This paper investigates the concept of alienation in Karl Marx, reviewed by Friedrich Müller, from the perspective of Rousseau, Hegel, and Marx. If alienation is a central category of Marx's thought, in fact, this concept was already formulated by Rousseau, remaining current in societies with a market economy, especially those part of the so-called periphery of capitalism. In this regard, it is noted manifestations of the phenomenon of alienation in societies like Brazil, especially during the experience of the 2005-06 "political crisis" that befell President Lula's government. It is here that one can check also the perverse aspect of alienation.
\end{abstract}

KEYWORDS: Alienation; Peripheral Capitalism; Brazilian politics.

Ora essa! Então é possível que andando comigo há tanto tempo, ainda não tenhas visto que todas as coisas dos cavaleiros andantes parecem quimeras, tolices e desatinos, e que são todas feitas pelo avesso? Não é que sejam realmente assim, mas simplesmente porque há sempre, entre nós, uma caterva de feiticeiros, que todas as coisas mudam, transformam e invertem, conforme seu gosto e segundo tenham vontade de favorecer-nos ou destruir-nos. (Dom Quixote. ${ }^{1}$ )

I.

O Professor Friedrich Müller publicou em 1985 a segunda edição de importante trabalho do conjunto de sua obra: Entfremdung, que pode ser traduzido como "Alienação" em vernáculo. Como subtítulo, o livro adverte-nos de que serão tratados os problemas resultantes da fundamentação antropológica da teoria do Estado em Rousseau, Hegel e Marx. Um ambicioso projeto intelectual, realizado com maestria por

\footnotetext{
* Universidade de Fortaleza - UNIFOR.

${ }^{1}$ CERVANTES, Miguel de. D. Quixote de la Mancha. Trad. Almir de Andrade e Milton Amado. v. I. São Paulo: Ediouro, 2004, p. 357.
} 


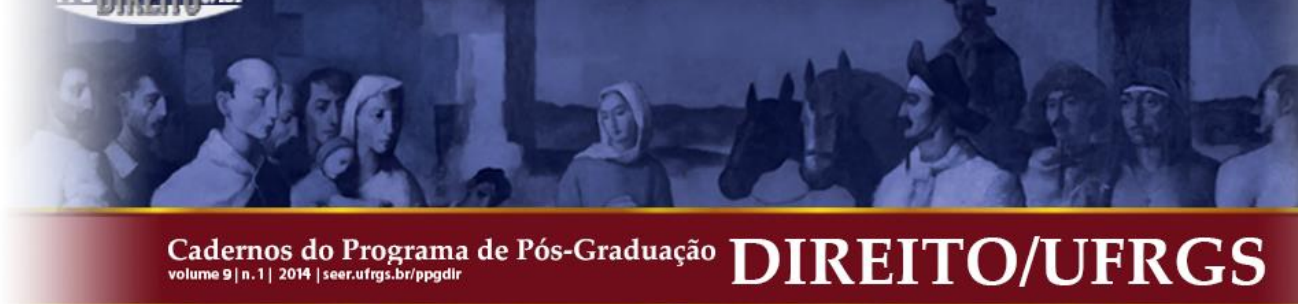

seu Autor. Não planejo de escrever uma resenha à obra. O que intenciono é, em virtude da atualidade das reflexões de Friedrich Müller nesse trabalho demonstrada, procurar, a partir de tais elaborações, formular alternativas explicativas para o fenômeno da política, que mesmo se reivindicando democrática após o impacto mundial da queda do muro de Berlin, não conseguiu minimizar o fenômeno da alienação, inerente a ordem capitalista, exibindo-se mesmo, essa democracia, como fortemente limitada nesse sentido e não somente nas sociedades da periferia do capitalismo.

Tentarei, portanto, enfrentar apenas duas indagações, reconhecendo, desde já que, se tanto perguntas como repostas carecerão de maior aprofundamento, não me parece inválida uma perspectiva "programática" a teorizar sobre a realidade políticoinstitucional brasileira a partir de junho de 2005. A primeira de minhas indagações é precisamente sobre a natureza da força da alienação na política, especialmente diante do desenvolvimento dos meios de comunicações e de sua sofisticação em, também e ao contrário do que se poderia imaginar, não conduzir necessariamente as sociedades na direção de processos emancipatórios, mas sim de exatamente fortalecer os adversários políticos de qualquer desses processos. Decorrente dessa primeira pergunta, passarei à segunda, na perspectiva de detectar a concreta manifestação da força da alienação em sociedades da chamada periferia do capitalismo, considerados os episódios da política brasileira, notadamente a partir da vitória do Partido dos Trabalhadores na eleição de 2002. Se é verdade que passados somente três dos quatro anos de um governo de esquerda qualquer busca em analisar referida experiência governativa pode parecer prematura, por outro lado não há como deixar de reconhecer que nesses três anos a sociedade brasileira vivenciou níveis elevados de conflitos e tensões inerentes ao regime democrático quase desconhecidos de sua experiência políticas. Novamente, muito des sa tensão derivou do papel dos meios de comunicação, a ponto de produzir lugares-comuns em análises de respeitáveis reputações acadêmicas e políticas. Neste local onde se movimentaram atores de toda sorte, a alienação - cujo significado também procurarei explicitar - exerceu uma função fundamental: a de transformar a fantasia em realidade, conferindo àquela a força desta última, não para singelamente não permitir que se vá 
além das aparências, mas para se construir uma representação do real com esta aparência. Evidente que não há como escapar da tentação de, num breve comentário sobre a situação brasileira, discorrer sobre a "crise política" desencadeada a partir das denúncias que se abateu sobre o governo, e que envolveram fortemente o Partido dos Trabalhadores $^{2}$. Neste ambiente, as limitações ainda são mais incisivas, já que o aspecto temporal - a análise do presente - surgirá como um obstáculo de difícil transposição. Afinal, como já percebia Antonio Gramsci, fase alguma do desenvolvimento histórico poderá ser compreendida e analisada senão após haver findado todo o seu processo de desenvolvimento e não durante o próprio processo, a não ser que se tenha claro tratar-se apenas de uma hipótese e como tal declará-la. Ainda, para Gramsci, sabe-se que uma estrutura corresponde ao passado real, porque ela é o testemunho, o "documento-prova" do que foi realizado e continua a subsistir como condição do presente e do futuro. O diálogo desta premissa com a alienação, para possibilitar a conjugação da "crise" de um governo que se reivindica de esquerda no Brasil com seus efeitos na qualidade política de nossa democracia, pode ainda oferecer um outro olhar sobre a mesma democracia; olhar este que irá além do quadro descritivo do empirismo, no instante em que se decide pelo enfrentamento teórico para fora dos limites aparentes que, normalmente e de maneira exuberante, insinuam-se como últimos definidores do processo político brasileiro.

Dessa forma, procurarei detectar um sentido material de alienação por meio de seu acúmulo histórico objetivo, para, em seguida, comentar sua desenvoltura no processo de democratização brasileiro, como afirmei, nos últimos tempos da política brasileira. Estou convencido, dessa maneira, de que a obra do Professor Friedrich Müller a que me referi, fornece importantes ferramentas para esta finalidade.

\footnotetext{
${ }^{2}$ Para Marilena Chauí fica evidente “ (...) que não é crise nenhuma, trata-se é da luta de classes, ao vivo e em cores. Pra ninguém botar defeito. Infelizmente, nem o governo nem o PT, a não ser algumas vozes muito isoladas, foram capazes de perceber isso" (CHAUÍ, Marilena. Por trás da crise está a luta de classes. Entrevista a Natalia Vianna et ali. Revista Caros Amigos, São Paulo, n 104, novembro de 2005, p. 31).
} 
Para F. Müller, é Rousseau - e não Marx - o primeiro a diagnosticar a alienação como uma "categoria central" ${ }^{3}$ dos novos tempos na Europa iluminista. Onde fundamenta F. Müller tal assertiva? Na constatação de que, aquilo que se denomina de "incapacidade" de Rousseau em expressar suas manifestações políticas, consiste exatamente no fortalecimento de sua doutrina, uma vez que as formulações de Rousseau libertar-se-iam do peso de premissas histórico-metafísicas. Dessa forma, para Müller, a história aparece em Rousseau tanto na forma de um crescente protocolo de autoalienação, como "ao mesmo tempo num cenário do irromper da liberdade não mais alienada do homem em sociedade" ${ }^{4}$. Presentes estariam, então, em Rousseau elementos históricos objetivos, concretos da polarização emancipação/desemancipação ${ }^{5}$, antecipando uma tensão política mais tarde reformulada na perspectiva revolucionária, como realizará $\mathrm{Marx}^{6}$. O que parece evidente é a compreensão material de Rousseau a respeito do fenômeno da alienação na história política, precedendo aos teóricos materialistas; opinião também compartilhada por Tom Bottomore e Mézarós ${ }^{7}$.

\footnotetext{
3 MÜLLER, Friedrich. Entfremdung - Folgeprobleme der anthropologischen Bergründung der Staatstheorie bei Rousseau, Hegel, Marx. 2. bearbeitete und stark erweiterte Auflage. Berlin: Duncker \& Humblot, 1985, p. 60. No original: "Rousseau ist der erste Diagnostiker der Entfremdung als einer der Zentralkategorie der europäischen Neuzeit".

${ }^{4}$ Id. Ibid., p. 60. No original: “ (...) zugleich als Spielfeld des Aufbruchs in nicht länger entfremdete Freiheit des gesellschaftlichen Menschen“.

${ }^{5}$ Utilizo aqui a oportuna análise de Domenico Losurdo: Democracia e Bonapartismo. RJ/SP: Ed. UFRJ/UNESP, 2004, p. 102ss.

${ }^{6}$ Aqui já um primeiro lugar-comum que pode ser desmistificado, e que, ao mesmo tempo, tão caro tem custado à esquerda mundial: a afirmação de que a visão de Marx não tem preocupações com democracia. É necessário que se entenda que a democracia em Marx ocupa um "um lugar segundo, e não secundário", já que seu pensamento é eminentemente um pensamento revolucionário, como insiste Jacques Texier (Democracia e revolução em Marx e Engels. Trad. Duarte Pacheco Pereira. Rio de Janeiro: Ed. UFRJ, 2005, p.15).

${ }^{7}$ BOTTOMORE, Tom. Dicionário do Pensamento Marxista. Rio de Janeiro: Jorge Zahar Editor, 1988, p. 5: "Mas provavelmente não há nenhum pensador antes de Hegel que possa ser lido e compreendido em termos da alienação e desalienação melhor do que Rousseau". Cf. István Mézários: Marx's Theor of Alienation, pp. 48 e ss; na edição brasileira, pp. 50 e ss.
} 
Ainda na esteira do pensamento de Rousseau, anota Müller, que o conceito da desigualdade econômica entre os homens considera o domínio de alienados sobre também alienados; tanto dominados como dominadores estão alienados de seu real papel numa sociedade ${ }^{8}$. No que diz respeito à alienação própria entre escravos e senhores nas suas inter-relações, pontua Friedrich Müller as distintas concepções que separam Hegel de Rousseau. Para o segundo, a compreensão que o escravo tem de si enquanto escravo e o senhor, enquanto senhor, e não na qualidade de homens, redunda na alienação de sua própria existência. Analisada a situação ante o prisma da alienação a que a existência da propriedade privada conduz o homem, outra não pode ser a conclusão de que o sentimento de liberdade terá que enfrentar a alienação para o estabelecimento de homens livres entre si e que se compreendam na sua condição de iguais ${ }^{9}$. O lugar central no pensamento marxiano da alienação, como não poderia deixar de ser diferente, possui uma tradição que, ainda que não corresponda à "maturidade materialista" adotada por Marx, deita suas raízes nas formulações iluministas. Não se trata aqui de discutir até que ponto Marx era um iluminista ou não. As discussões dos conhecidos "Neukantianer" da primeira década do século XX desenvolveram esforços razoáveis na disputa entre ideais iluministas e o socialismo ${ }^{10}$. O que parece permanecer atual é, pois, como o pensamento que se reivindica emancipatório e essencialmente revolucionário (lembrado por Jacques Textier aqui transcrito), pode ganhar a partir do Iluminismo e de seu também potencial libertário, como lembra Max Adler ${ }^{11}$.

\footnotetext{
${ }^{8}$ Müller, Friedrich: Enfremdung, p. 61/62. No orginal: "Für Rousseau ist dagegen die Ungleichheit ökonomischer Institutionen die Folge der alles verderbenden Herrschaft entfremdeter Meschen über entfremdeter Menschen; ist Herrschaft nicht etwas sich Überlenbendes, sondern etwas in die moralische Freiheit nicht lönger sich selbst entfremdeter Bürger eines homogenen Gesetyesstaates Aufzuhebendes“. 9 MÜLLER, Friedrich. Entfremdung - Folgeprobleme der anthropologischen Bergründung der Staatstheorie bei Rousseau, Hegel, Marx. 2. bearbeitete und stark erweiterte Auflage. Berlin: Duncker \& Humblot, 1985, pp. 50ss.

${ }^{10}$ Por ocasião do primeiro centenário de Kant, celebrado em fevereiro de 1904, surgiu o debate no espaço germânico de cultura, que ocupou boa parte dos intelectuais como Franz Staundiger, Franz Mehring, Hans Jörg Sandküler, Max Adler. Tais autores, dentre outros, refletiram sobre um possível diálogo entre Kant e Marx, posicionando-se ora favoravelmente à sua possibilidade, ora contra.

${ }^{11}$ Cf. ADLER, Max. Kant und der Sozialismus [1904]. In: SANDKÜHLER, Hans Jörg; VEGA, Rafael de la (Hrsgg.). Marxismus und Ethik - Texte zum neukantianischen Sozialismus. Mit einer neuen Einleitung von Hans Jörg Sandkühler. Frankfurt/M.: Suhrkamp, 1974, pp. 134-156.
} 
O que a reflexão de Friedrich Müller permite, com o olhar para o acúmulo histórico numa perspectiva progressista, é a reatualização de um conceito político, como aquela da alienação, que ainda demonstra todo o seu vigor nas sociedades industriais, transcorridos mais de cento e cinquenta anos. Novamente, não se trata aqui de dizer que a descrição da aplicabilidade do termo alienação não sofreu alterações desde os tempos dos Manuscritos de Karl Marx até os dias atuais, porém de se reconhecer que a formulação do conceito permanece como dos mais poderosos instrumentos de manutenção da ordem capitalista, uma vez que a dimensão do processo de alienação detém sua gênese na "venda" da força de trabalho do homem para outro homem.

III.

O conceito de alienação se encontra no centro do pensamento do Marx d' $O s$ Manuscritos Econômico-Filosóficos do ano de $1844^{12}$. Isso possibilitaria a explicação dos motivos pelos quais Marx entende a alienação como um fenômeno, primeiramente, advindo da economia. Mas as coisas não ficam por aí. R. Aron resume a dimensão do conceito em Marx, que, mesmo em 1844, escapa das tentações do simplesmente econômico. Aron enumera então as formas de alienação no Marx dos Manuscritos: "Forma $\mathrm{n}^{\mathrm{o}}$ 1: o trabalhador produz um objeto que se torna estranho a ele; Forma $\mathrm{n}^{\mathrm{o}} 2$ - o trabalhador é alienado no trabalho mesmo, porque o trabalho que deveria ser a atividade genérica passa a ser apenas o meio a serviço do ser biológico ou animal; Forma $\mathrm{n}^{\circ} 3$ essa alienação do trabalhador em relação ao produto de seu trabalho e em relação a seu trabalho acarreta nas relações dos homens entre si, sob a dupla forma do domínio do não-trabalhador sobre o trabalhador e da mediatização pelo dinheiro de todas as relações humanas"13. Se o início se dá com a reflexão sobre economia política (na versão original Marx utiliza o termo Nationalökomonie) e a posição dos economistas no capitalismo, a conclusão de Marx, registrada por Aron, de que “(...) as conseqüências a que chegam os

\footnotetext{
12 ARON, Raymond. O Marxismo de Marx. Trad. Jorge Bastos. São Paulo: Editora Arx, 2004 , p. 150.

${ }^{13}$ ARON, Raymond. O Marxismo de Marx. Trad. Jorge Bastos. São Paulo: Editora Arx, 2004, p. 163.
} 
conceitos e raciocínios dos economistas são humanamente escandalosas" ${ }^{14}$, denuncia de maneira evidente que a preocupação humanista/iluminista está presente nas suas ideias, igualmente desde os primórdios dos trabalhos de Marx, e conduzirá sua filosofia revolucionária. É o inconformismo com a perversidade da economia capitalista - ou melhor, o desprezo da economia política pelas condições que lhe são externas - a espalhar e perpetuar a desigualdade entre os homens, usurpando-lhes sua consciência; inconformismo aliado da firme convicção de que esses mesmos homens podem mover os rumos da história, é que o pensamento emancipatório de Marx penetrará profundamente nas mentes do século XX, consistindo em parâmetros para as ações hodiernas de agentes movidos pelos mesmos propósitos libertários.

R. Aron não está sozinho nessa posição interdisciplinar de Marx no que envolve o conceito de alienação. István Mészáros explicita da mesma forma o alcance do conceito marxista de alienação, bem como sua importância para a construção deste pensamento: “(1) the manifestation of labour's itself in reality, together with the various institutionalizations, reifications and mediations involved in such a practical selfalienation, i.e. WAGE LABOUR, PRIVATE PROPORTY, EXCHANGE, MONEY, RENT, PROFIT, VALUE, ETC., ETC.; (2) the reflection of these alienations through religion, philosophy, law, political economy, art, "abstract material" science, etc.;" ${ }^{15}$. Sublinhei a segunda conclusão de Mézáros porque entendo ser ela fundamental para a quarta parte deste pequeno escrito: é que nela está contida a visão de um Marx, desde seus mais jovens trabalhos, atento à pluralidade dos fatores que atuam na vida em sociedade e o relacionamento interior/exterior de tais fatos, a formarem a estrutura do sistema capitalista. Dissociar tais aspectos uns dos outros corresponderia a compreender a sociedade e seus constantes movimentos como sem força própria; produzidos e reproduzidos por agentes a eles externos, o que corresponderia, na linguagem do próprio Marx, a "por tudo de pernas para o ar".

\footnotetext{
${ }^{14}$ Id. Id., 156.

15 MÉZÁROS, István. Marx's Theory of Alienation. New York/Evanston/San Francisco/London: Harper\&Row Publishers, 1972, p. 99 (v. edição brasileira: Marx: A Teoria da Alienação. Trad. Waltensir Dutra. Rio de Janeiro: Zahar Editores, 1981, p. 92).
} 
IV.

O conceito de alienação adquiriu importância não somente pelo fato de ter se tornado uma característica central do pensamento de um filósofo como Marx, mas ainda porque inaugurou um novo rumo no pensamento mundial, precisamente: demonstrar que a tarefa da filosofia, além de descer do céu para a terra, é aquela de que nada deve ser aceito por tradição ou costume. Em outras palavras, a filosofia deve ser a arma contra a ilusão; a ilusão do primeiro momento que se converte em tentação para a explicação fácil da realidade que se tem diante dos olhos, na louca busca de se encontrar um esclarecimento teórico que a tudo socorra em todos os lugares e tempos ${ }^{16}$. Logo no início de seus Manuscritos, um jovem Marx de vinte e quatro anos não deixa por menos: a definição dos economistas e da economia política de salário nada mais é do que uma simples ilusão, ou melhor, uma ilusão construída para um determinado fim: possibilitar a acumulação do capital, mantendo o trabalhador com um nível de remuneração que apenas não permita sua extinção, já que essa é a razão de sua necessidade para o sistema econômico do capitalismo, isto é, vender sua força de trabalho como um animal ao capitalista. Porém, o que denuncia o caminho que Marx escolherá para sua obra já surge aqui, especificamente quando é por ele explicitado o tratamento abstrato que a economia

\footnotetext{
${ }^{16}$ HORKHEIMER, Max. Die gesellschaftliche Funktion der Philosophie. In: Max Horkheimer: Kritische Theorie - Eine Dokumentation. Hrsg. von Alfred Schmidt. Frankfurt/M.: S. Fischer Verlag, 1968, pp. 296/297. "A resistência da filosofia contra a realidade deriva de seus princípios imanentes. A filosofia insiste em que a ação e os objetivos do homem não devem ser produtos da necessidade cega. (...) $\mathrm{O}$ impulso da filosofia direciona-se contra a mera tradição e a resignação nas questões fundamentais da existência; ela tem a ingrata tarefa de trazer a luz da consciência sobre qualquer relação humana e suas reações, de forma tão enraizada, que elas naturalmente pareçam imutáveis e eternas”. No original: „Der Widerstand der Philosophie gegen die Realität rührt aus ihren immanenten Prinzipien. Philosophie insistiert darauf, daß die Handlungen und Zielen der Menschen nicht das Produkt blinder Notwendigkeit sein müssen. (...) Der Impuls der Philosophie richtet sich gegen bloße Tradition und Resignation in den entscheidenden Fragen der Existenz; sie hat die undankbare Aufgabe übernommen, das Licht des Bewußtseins selbst auf jene menschlichen Beziehungen und Reaktionsweisen fallen zu lassen, die so tief eingewurzelt sind, daß sie natürlich, unveränderlich und ewig scheinen".
} 
política dedica ao trabalho ${ }^{17}$. Num momento posterior dos Manuscritos, Marx analisa o trabalho alienado. Assim, a disposição da economia política é esconder a alienação, quando de sua recusa em examinar o vínculo imediato entre trabalhador e produção ${ }^{18}$. Qual a principal consequência de uma realidade formada a partir dessas premissas para Marx? A alienação do homem, que se torna animal, distanciando-se, alienando-se, portanto, de sua condição humana: "Alcança-se o resultado de que o homem (o trabalhador) somente será livremente ativo no desempenho de suas funções animais comer, beber e procriar, e, quando muito, na moradia, adorno etc. - enquanto que nas funções humanas se vê reduzido a um animal.O elemento animal torna-se humano, e o humano transforma-se em animal" ${ }^{\prime 19}$. Nesse ponto, surge uma visão antropológica de Marx sobre o homem: a do chamado "ser genérico" (Gattungswesen). O homem é um ser que possui uma relação consigo e com sua espécie. Tal qual um animal, o homem possui necessidades, mas esse homem difere do animal por suas pretensões além do meio físico que ao animal não é possível em razão da ausência de uma inteligência. A exclusão do homem deste último elemento, torna-o alienado, distante, consequentemente, de sua própria condição humana. Dessa forma, a atividade do trabalho no capitalismo aliena o homem porque "1) aliena a natureza do homem, e 2) aliena-o de si próprio, alienando o homem a respeito de sua espécie, transformando a vida genérica em meio de vida individual. Primeiramente, aliena a vida genérica e a vida individual; e, em segundo lugar, muda esta última na sua abstração em objetivo daquela primeira, portanto, na sua forma abstrata e alienada" 20 . Por isso é que a propriedade privada, como resultado do

\footnotetext{
${ }^{17}$ MARX, Karl. Ökonomisch-philosophische Manuskripte aus dem Jahre 1844. In: Marx-Engels Werke. Ergänzungsband. Berlin: Dietz Verlag, 1968, pp. 475 e 481 (na tradução portuguesa, referenciada na bibliografia, pp. 107 e 115 , respectivamente).

18 Id. ibid. p. 513 (trad. portuguesa, p. 161). No original: "Die Nationalökonomie vergibt die Entfremdung in dem Wesen der Arbeit dadurch, daß sie nicht das unmittelbare Verhältnis zwischen dem Arbeiter (der Arbeit) und der Produktion betrachtet".

${ }^{19}$ Id. ibid., pp. 514/515: "Es kömmt daher zu dem Resultat, daß der Mensch (der Arbeiter) nur mehr in seinen tierischen Funktionen, Essen, Trinken und Zeugen, höchstens noch Wohnung, Schmuck etc., sich als freitätig fühlt und in seinen menschlichen Funktionen nur noch mehr als Tier. Das Tierische wird als Menschliche und das Menschliche als Tierische" (trad. Portuguesa, p. 162).

${ }^{20}$ Id. ib., p. 516. No original: "Indem die entfremdete Arbeit die Menschen 1. die Natur entfremdet, 2. sich selbst, seine einige tätige Funktion, seine Lebenstätigkeit, so entfremdet sie dem Mensch die Gattung; sie macht ihm das Gattungsleben zum Mittel des individuellen Lebens. Erstens entfremdet sie das Gattungsleben und das individuelle Leben, und zweitens macht sie das letztere in seiner
} 


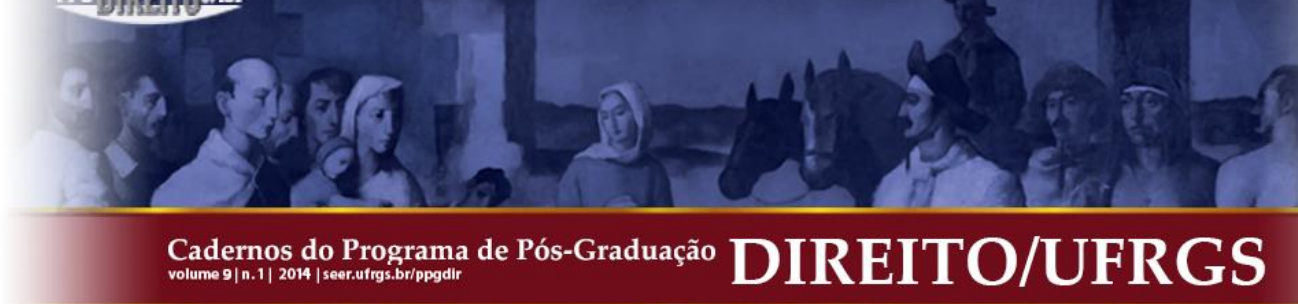

capitalismo, deriva do trabalho alienado, vale dizer, do homem alienado. Aqui está lançada a base da crítica que estará presente nas futuras investigações de Marx, ou seja, a propriedade privada como primeiro elemento caracterizador do capitalismo, e, como seguimento interpretativo, a forma desumana de organização econômica e política das sociedades modernas. Nesse instante Marx estende o conceito de alienação não somente ao lado da análise da economia política, mas dilata tal conceito para a vida em sociedade. Que isso é um evidente denotativo de que para Marx - e Engels - a economia não explicava tudo, não me proponho a discutir aqui. O que saliento é, pois, que a categoria marxiana da alienação não se encerra na economia, abrangendo, como ele próprio afirma, todos os "sentidos físicos e intelectuais que forma substituídos pela simples alienação de todos os sentidos, pelo sentido de ter" ${ }^{21}$. Tal referência significa que todas as relações da sociedade capitalista são mediadas pelo ter, pelo dinheiro, que traduz todas as formas de relação, abandonando o homem sua verdadeira vida genérica, conduzindo-se de maneira animal - mesmo nas relações emocionais ${ }^{22}$. A difícil atribuição da liberdade nesse quadro consiste na emancipação humana de todos, que não terá como deixar de enfrentar a dissolução da propriedade privada, na direção da sociedade comunista. Por esse motivo é que a "eliminação da propriedade privada se constitui na emancipação total de todos os sentidos e qualidades do homem; mas somente é emancipação porque todos os ditos sentidos e qualidades se tornaram humanos, objetiva e subjetivamente" ${ }^{23}$.

Abstraktion zum Zweck des ersten, ebenfalls in seinen abstrakten und entfremdeten Form" (trad. portuguesa, p. 164).

${ }^{21}$ Id. ibid. p. 540. No original: "An die Stelle aller physischen und geistigen Sinne ist daher die einfache Entfremdung aller dieser Sinne, der Sinn des Habens getreten" (trad. portuguesa, p. 197).

${ }_{22}$ Id. ibid., p. 566: "Uma vez que o dinheiro, enquanto conceito existente e ativo, confunde, distorce todas as coisas, é ele a confusão e a distorção de todas as coisas, ou seja, um mundo invertido, a confusão e distorção de todas as qualidades naturais e humanas". No orginal: "Da das Geld als der existierende und sich betätigende Begriff des Wertes alle Dinge verwechselt, vertauscht, so ist es die allgemeine Verwechslung und Vertauschung aller Dinge, also die verkehrt Welt, die die Verwechslung und Vertauschung aller natürlichen und menschlichen Qualitäten" (trad. portuguesa, p. 234).

${ }_{23}$ Id. ibid., p. 540. No original: "Die Aufhebung des Privateigentums ist daher die vollständige Emanzipation aller menschliche Sinne und Eigenschaften; aber sie ist diese Emanzipation grade dadurch, daß diese Sinne und Eigenschaften menschlich, sowohl subjektiv als objektiv, geworden sind" (trad. portuguesa, p. 197). 
A alienação reveste-se, pois, numa categoria da reflexão de Marx que vai além do econômico, presente nas formas de organização das sociedades capitalistas, já que sua essência é a propriedade privada. Equivocada é a ideia de que mesmo na sua origem o conceito marxiano de alienação esteja imobilizado pelos parâmetros da economia, ou ainda da economia política. O que mais se assemelha à perspectiva de Marx é o fato de que a alienação surge nos primeiros momentos de sua obra não como vinculada á economia, porém como espaço integrante da visão crítica a distinguir a reflexão marxista. Dessa forma, a alienação não surge numa obra de análise econômica porque é concebida originalmente apenas como um elemento da economia, mas, ao contrário, a análise econômico-política de Marx é que surge como uma oportunidade concreta, objetiva de demonstrar como a alienação integra todos os sentidos e qualidades da vida no capitalismo, representada, dessa maneira, por um dos pilares do capitalismo, notadamente o da propriedade privada. Assim como nas artes, na política, na religião, no direito etc., a alienação também se apresenta como mecanismo de guarda de uma dada ordem, uma vez que essa alienação do homem diante de si próprio é que se converterá em ferramenta da solidez do capitalismo. O não domínio do homem sobre si, a redução de suas qualidades humanas à condição de animal, sua desimportância enquanto ser genérico para o sistema de produção do capitalismo, a satisfação de suas necessidades elementares para que continue existindo somente em tal raio de atuação ganham em significado quanto mais se moderniza o acúmulo do capital. É que, como bem demonstra Marx, quanto mais riqueza uma sociedade capitalista produz mais pobre restará o trabalhador, mais distante do capital e dos bens para os quais emprestou sua força física e não física de trabalho ele permanecerá. Se as sociedades atuais do dito "Primeiro Mundo" realizaram igualdades entre suas extensas camadas, muito mais está a se confirmar Marx do que a desacreditá-lo. Não se pode esquecer que quatro anos após os Manuscritos de 1844, Marx e Engels elaboraram o Manifesto do Partido Comunista, conclamando todos os trabalhadores a uma aliança mundial, única forma de superação do capitalismo. E foi exatamente a organização dos trabalhadores e de outros atores sociais e políticos ao longo de todo o século XIX que domesticou o capitalismo, fazendo com que boa parte da riqueza das nações europeias fosse melhor dividida, ainda que a 
exploração da força de trabalho tenha se deslocado para outros cantos do mundo. Possuidor de uma imanência dialógica, o conceito de Marx de alienação vem a confirmar o que se afirmou no início deste texto: a herança iluminista em Marx não somente é patente - democracia, emancipação, universalidade como exigência da libertação de todos no mundo - como ainda está por ser melhor explorada, a fim de garantir ao seu pensamento a reverência devida.

A centralidade do conceito de alienação em Marx não se perde no tempo, e há indícios de sua atualidade para o século XXI. Inquestionável a recente condição da comunicação e da linguagem nas sociedades após a II Guerra Mundial. O surgimento da teoria da ação comunicativa de Jürgen Habermas talvez seja o mais sofisticado momento dos rumos da filosofia do século XX, e com referida reflexão filosófica, a discussão em torno de comunicação e linguagem, de esfera pública e participação de todos nos processos decisórios da política adquiriram contornos então impensáveis para grande parte dos teóricos sociais de até bem pouco tempo atrás. Recorrendo ainda a Habermas, o conceito por ele desenvolvido de "colonização do mundo vivido (Lebenswelt)" e de mediação entre a sociedade por meio de participantes em igualdade de ponderações não significa um idealista desejo de que todos tenham o mesmo nível de comunicação e que essa seja a solução para os tempos onde a barbárie da humanidade foi realizada.

Por outro lado, a retomada do mundo vivido pela comunicação sugere uma clara recuperação a ser efetivada pelos novos registros da comunicação, no sentido de não serem as relações sociais mediadas exclusivamente pelo dinheiro e por seus significados a imporem situações decisórias padronizadas, as quais, caracterizadoras de ações não emancipatórias, não têm como abandonarem o território da alienação. Se os dilemas da comunicação, a enfrentarem questões como as de integração de culturas, etnias e religiões distintas (em outras palavras: cristãos e mulçumanos nos difíceis dias de hoje), detêm diante de si um enorme desafio, de outra maneira não há como se subestimar que a informação de que dispõem as sociedades atuais tem pautado a agenda dos processos decisórios, e é por intermédio da construção da esfera pública de 
informação que a heterogeneidade das tensões políticas abandona o terreno do abstrato, vencendo sua forma metafísica para construir realidades, enfraquecer corajosos e fortalecer covardes. Não sem razão, constatou Wanderley Guilherme dos Santos que "Não é da escassez da informação que padecem [as sociedades da América Latina], mas da abundância de informação caolha, sendo sua mais importante fonte o retrato que, cotidianamente os meios de comunicação distribuem à opinião pública nacional e internacional. (...) Ainda mais pernicioso do que ocasionar desastres individuais é o mau serviço que se presta não somente ao regime democrático, mas à verdade dos fatos, quando se generaliza, levianamente, a toda a classe política deficiências que são personalizadas" 24 . É a partir desse ponto que relaciono a concepção marxiana de alienação - mantendo seu sentido sempre dialógico com outros nichos da sociedade que não o estritamente econômico - tanto com a atualidade da informação que se pratica na conhecida esfera pública de países como o Brasil, como com a recente e insistentemente denominada “crise política" que se desenvolve desde o mês de junho de 2005.

É aconselhável - ou razoavelmente seguro, do ponto de vista teórico - trilhar esse caminho? Como disse, a alienação surgiu em Marx num momento seu de reflexão econômica, o que pode sugerir que tal conceito, além de ter perdido em sua atualidade, somente possui aplicação e sentido desde que vinculado aos limites das relações econômicas do conflito capital e trabalho do século XIX, ou seja, dos momentos finais da Revolução Industrial, os quais se distanciam em muito das relações de trabalho do século XXI, com o predomínio da linguagem e de suas consequências. Em outras palavras, não seria arriscado reatualizar um conceito filosófico central da obra de Marx, ainda mais com a "crise política" do Brasil? É possível, mas o risco vale a pena, na perspectiva de incluir mais elementos em tão importante momento da experiência democrática brasileira. Além dessa tentação acadêmica a que me referi, desejo registrar que esforços nesse mesmo sentido não representam novidades, menos ainda inédita

${ }^{24}$ SANTOS, Wanderley Guilherme dos. A Universalização da Democracia. In: BENEVIDES, Ma. Victoria; VANNUCHI, Paulo; KERCHE, Fábio (Orgs.). Reforma Política e Cidadania. São Paulo: Instituto Cidadania/Editora Fundação Perseu Abramo, 2003, pp. 34-35. 


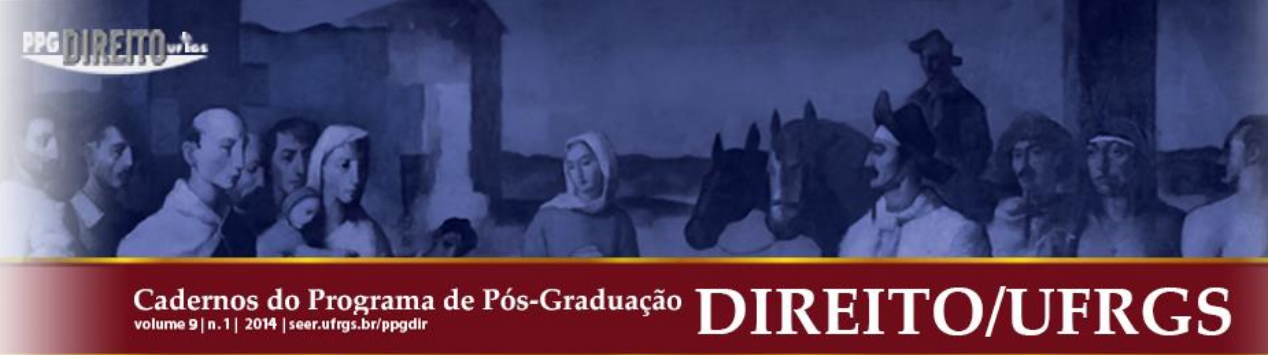

busca de explicação fácil para todas as realidades políticas do planeta. Sonja Buckel traz importantes ponderações a respeito de uma nova teoria materialista do Direito ${ }^{25}$, com a alusão ao momento da totalidade concreta (konkrete Totalität), o que diferenciaria, por exemplo, a recepção do marxismo na Alemanha daquela de outras nações, como a França. Apoiada na visão da Escola de Frankfurt, Buckel insiste noutro redimensionamento - de matriz marxista - da totalidade, como visto por Adorno: “a totalidade concreta significa aqui que ela depende das unidades, que é uma estrutura adicionada do lado dos momentos unitários, sem se deixar logicamente abstrair de tal contexto. Ela contém muito mais em si todos os momentos unitários como condição de suas próprias possibilidades. Referida representação deixa-se exprimir num modelo circular: a circulação do todo somente pode funcionar quando existem momentos unitários $(\ldots) " .26$

A totalidade concreta de que se discorre implica, portanto, no reconhecimento realizado pela teoria materialista de que a economia significa um complexo de relações unitárias tão sofisticado - tal qual o arte, o direito, a política, a sexualidade, a sociologia etc., que é impossível se falar da preponderância da economia sobre os demais fatores da vida em sociedade. Uma jovem autora alemã, Andrea Maihofer, compartilha dessa leitura de Marx e de sua compreensão de sociedade: "Marx afirma que a origem do direito está tanto na esfera econômica quanto fundamentado nas relações de vida materiais de uma sociedade. Segundo ele, uma determinada forma social nada mais é que uma combinação de distintas formas de produção sob a dominação de uma forma de produção. O total de uma esfera econômica, de relações de vida materiais numa determinada formação social advém de múltiplos fatores. (...) Em

\footnotetext{
${ }^{25}$ BUCKEL, Sonja. Neo-Materialistische Rechtstheorie. In: BUCKEL, Sonja; CHRISTENSEN, Ralph; FISCHER-LESCANO, Andreas (Hrsgg.). Neue Theorien des Rechts. Stuttgart: Lucius \& Lucius, 2006, pp. 117-138.

${ }_{26}$ Id. ibid., p. 131. No original: "Konkrete Totalität bedeutet dabei, dass von jener alles Einzelne abhängt, d.h. dass sie eine Struktur jenseits der Addition des Einzelmomente ist, ohne dass sie sich jedoch logisch davon abstrahieren ließe. Sie enthält vielmehr als Bedingung ihrer eigenen Möglichkeiten alle konkreten Einzelmomente in sich. Diese Vorstellung lässt sich in einem Kreismodell ausdrücken: der Gesamtkreislauf kann nur funktionieren, wenn es eigenständige Momente gibt (also eine vergleichbare Eigenständigkeit wie die der Instanzen bei Althusser)“.
} 


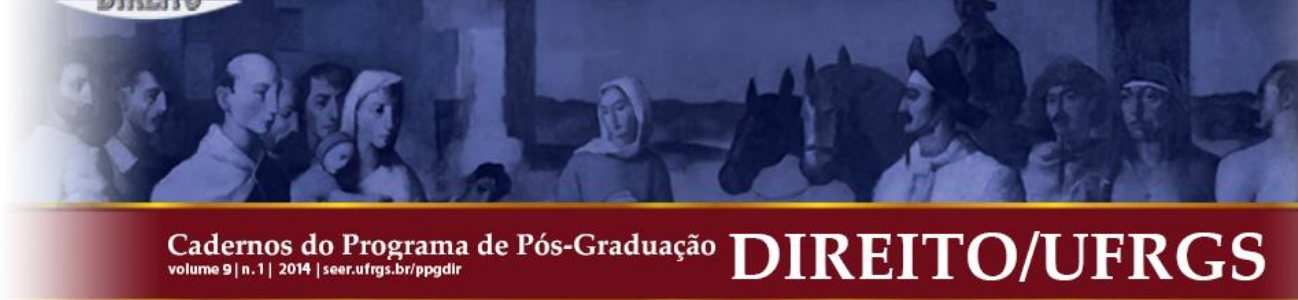

outras palavras, o total da esfera econômica é um rede de diferentes, igualmente históricas temporalmente desiguais relações, práxis tais quais formas sociais conscientes e neste sentido elaboradas" 27 . Dessa forma, além do diálogo entre as unidades integrantes da sociedade, domínio e predominância da economia traduzem mais uma distorção do que propriamente a visão que o materialismo de inspiração marxiano oferece. O entrelaçamento histórico e elaborado das diversas instâncias sociais é que traduzem as formas de produção de uma sociedade. E, exatamente, nessa elaboração de complexidade social, o elemento da alienação não está ausente. Não somente não está ausente, como se manifesta na "totalidade concreta" de uma dada formação social. Ainda que seja no Brasil!

V.

Em junho de 2005, o governo do Partido dos Trabalhadores viu-se, numa velocidade jamais experimentada em episódios semelhantes da história recente, completamente envolvido em denúncias de corrupção, que levou, em pouco mais de oito meses, à perda de mandatos políticos, queda de importantes Ministros de Estado, e, de um modo particularmente especial, obrigou o Partido a refletir sobre sua forma de atuação no governo. As denúncias partiram do Deputado Federal Roberto Jefferson (PTBRJ), que, em resumo, tornou do conhecimento público a existência de uma sistemática utilização de pagamento de propinas a parlamentares, por representantes do Governo, com o objetivo de aprovação de matéria legislativa de seu interesse. Tais pagamentos seriam feitos

\footnotetext{
${ }^{27}$ MAIHOFER, Andrea. Das Recht bei Marx. 1. Auflage. Baden-Baden: Nomos Verlagsgesellschaft, 1992, p. 150, No original: „Marx behauptet hiernach, die Entstehung des Rechts ist in der ökonomischen Sphäre gegründet bzw. in den materiellen Lebensverhältnissen einer Gesellschaft begründet. Eine historisch bestimmte Gesellschaftsformation ist ihm zufolge selbst wiederum eine Kombination verschiedener Produktionsweisen unter der Dominanz einer Produktionsweise. Die Gesamtheit einer ökonomischen Sphäre, der materiellen Lebensverhältnissen einer historisch bestimmten Gesellschaftsformations besteht also aus einer Vierzahl verschiedener, häufig auch historisch ungleichzeitiger, gesellschaftlicher Verhältnisse, Interesse und Praxen. Sie ist mit anderen Worten ein Netz verschiedenster, auch historisch ungleichzeitiger materieller Verhältnisse, Praxen sowie mehr oder weniger ausgearbeitet gesellschaftlicher Bewußtseinsform ".
} 
com conhecimento de altos funcionários do Governo, quando não sob determinação direta desses altos funcionários. Esse sistema de corrupção teria maior extensão, já que vinculado à arrecadação fraudulenta de recursos para campanhas eleitorais em favor dos candidatos do Partido dos Trabalhadores. Assim, bancos, empresas com relações contratuais com o Governo e com o Partido dos Trabalhadores, parlamentares, Ministros de Estado, políticos, operadores do mercado financeiro, seriam os responsáveis pelo maior escândalo de corrupção da história do Brasil, a sofrer seguidos desdobramentos com a entrada de novos atores em cena mais de um ano depois de instalada a "crise". A qualidade e o volume das denúncias não deixaram alternativas ao Congresso Nacional, a não ser aquela do caminho da investigação, por meio, principalmente, de uma Comissão Parlamentar Mista de Inquérito, bem como apuração das responsabilidades em trabalhos paralelos da Comissão de Ética, no âmbito da Câmara dos Deputados. O noticiário brasileiro nos meses de junho a dezembro de 2005, não perdeu um só desses momentos, havendo sido transmitidos depoimentos de diversas autoridades da República, e julgamentos no Câmara dos Deputados, acompanhados de toda sorte de comentários por parte de intelectuais, jornalistas e, claro, de políticos do governo e da oposição.

Naturalmente que esse ambiente político determinou a atuação dos meios de comunicação, tradicionalmente e em sua grande maioria hostis ao Partido dos Trabalhadores, ao Presidente Luís Inácio Lula da Silva, ao Movimento dos Trabalhadores Rurais sem Terra - MST. Recebeu especial comentário da mídia o argumento de que o lado "puro" do PT, ao longo de sua trajetória de vinte e cinco anos, nada mais era do que retórica vazia, tendo os escândalos não deixado dúvidas quanto a isso. O interessante - e o primeiro elemento objetivo a comprovar a mecânica do fenômeno da alienação enquanto qualificador na não autonomia do homem - é que o discurso dominante na imprensa durante os mesmos vinte e cinco anos anteriores à chega do PT na Presidência da República era de que o PT era imaturo, não detinha capacidade de governar por não conter seus radicalismos, além de sua intransigência na formação de alianças, o que impossibilitaria um eventual governo seu de governar. Em outras palavras, a concepção da política como moral era posta à ordem do dia com mais 
frequência quando o PT estava à frente da condução governativa. Óbvio que essa crítica não era direcionada aos partidos tradicionais, com seus caciques também tradicionais da política. Na qualidade de governantes, eram eles louvados como "habilidosos", "maduros", até mesmo pela ausência de maior interesse investigativo de seus acordos, campanhas eleitorais, contratos e nomeações para cargos públicos. Para um segundo momento, a moralidade a que o PT - na oposição - chamava a atenção pouco mais era do que uma visão moralista da política, infantil e que não merecia a atenção diante do realismo da política e de seus complexos nexos entre Estado e sociedade no Brasil. Não é sem explicação, portanto, que a defesa da "zona cinzenta da democracia" como uma fatalidade da própria democracia, elaborada por respeitável filósofo brasileiro para justificar fortes denúncias de corrupção durante o governo do Partido da SocialDemocracia Brasileira (PSDB), quase não obteve repercussão na imprensa nacional, a não ser por parte de alguns outros intelectuais, passando ao largo da percepção e debate dos mesmos jornalistas, e em todo caso, sem desencadear qualquer ação concreta seja sobre o teor da afirmação em si, seja sobre os episódios que a provocaram. A dinâmica desses fatos confirma de maneira objetiva a atualidade do conceito de alienação, e, a meu ver, não somente a procedência de sua formulação, porém a necessidade de sua inclusão para as análises sobre os tempos mais recentes da democracia brasileira.

De todo esse cenário, destaca-se como positivo as respostas que a institucionalidade brasileira, ancorada na Constituição Federal, tem conseguido oferecer até o momento. Corrido mais de um ano da chamada "crise política", instituições como Ministério Público, Poderes Judiciário e Legislativo, Polícia Federal etc. agem cada um segundo seus contornos constitucionais, investigando, julgando, funcionamento normalmente, enfim. É o caso de se perguntar onde reside mesmo a "crise" e em que medida a democracia no Brasil não está mais fortalecida, uma vez que não se conhece um governo tão investigado como o atual.

Retomo, então, minhas propostas de indagação iniciais. Como ver no desenvolvimento da chamada "crise política" as manifestações concretas da alienação. 


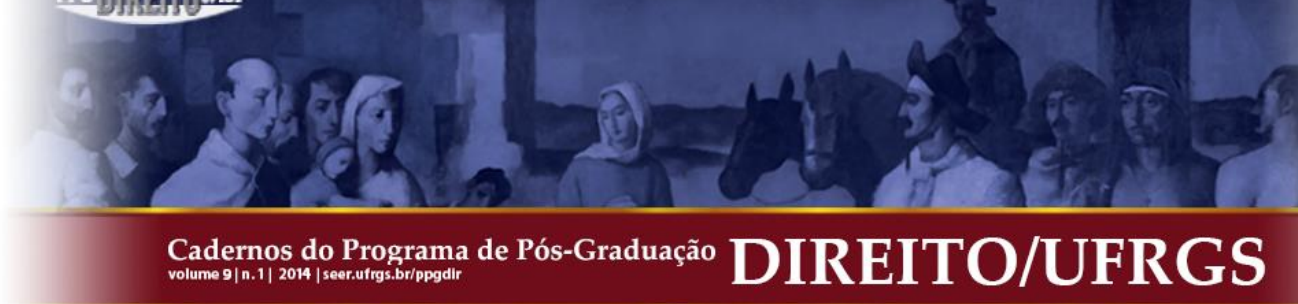

Se não há "crise" porque o funcionamento institucional do País não padece de ameaça mais séria, a presença da alienação deixa-se traduzir pelo fato de não ser essa visão também o conteúdo com que se exibe a "crise" perante a esfera pública (Öffentlichkeit). Pelo contrário: a imprensa insiste em mostrar a "crise" como a decadência da política brasileira, ideia alimentada por sempre constantes rancorosos escritos a desfrutarem de generoso espaço em meios de comunicação de circulação nacional.

Duas dimensões decorrentes desse quadro não passam desapercebidas e se conectam com a afirmação de que a alienação política não somente persiste, mas ainda é capaz de reproduzir o preconceito e o perverso. Dessa maneira, não há como abandonar a ideia de que a razão também produz o mal. Se Montaigne lembrou ser o sono da razão o responsável pela criação dos monstros, a história parece dar mais razão a Epicuro, Leibniz e Horkheimer, ao pensarem ser a razão dos homens a responsável pela vitória do mal e da perversidade. Marx, que teve seu momento epicurista e influenciador de Horkheimer que foi, viu na alienação a forma intencional de não liberdade, de não emancipação dos homens, isto é, o uso da razão para perpetuação do domínio escandaloso e terrível de uns sobre os outros, simplesmente em nome do acúmulo de riqueza, denunciado, do ponto de vista humanístico, o lado primitivo do capitalismo.

Recorri às duas dimensões para tentar mostrar a perversidade da política racional, tendo como alimentadora a alienação. A primeira delas foi muito bem lembrada por Luiz Werneck Vianna em recente trabalho. Ao comentar os desdobramentos recentes da vida política brasileira após a vitória do PT, afirma Vianna que "a história brasileira está absolvida" 28 . Dizer que nossa história está absolvida

\footnotetext{
${ }^{28}$ VIANNA, Luiz Werneck. Esquerda Brasileira e Tradição Republicana - Estudos de conjuntura sobre a era FHC-Lula. Rio de Janeiro: Editora Revan, 2006, p. 145. Diz literalmente o Autor: "A história brasileira está absolvida. Ela está absolvida por sua parte mais nova, por seu seres subalternos, por seus dirigentes novos, que sempre condenaram nossa história como errática, como uma história malfeita, com uma Independência malfeita, uma República malfeita, enfim, como uma história de desenganos. Esse diagnóstico foi corrigido agora, toda a nossa história foi revalorizada, porque, afinal, não pode ser tão malfeita uma história que permite essa conclusão - a vitória de um candidato popular nas urnas" (id. ibid., pp. 145/146).
} 
significa dizer que a construção da nação e do povo brasileira não é melhor, tampouco pior, do que a de nenhum outro. É uma história diferente. Essa interpretação de Werneck Vianna, além de recusar a hierarquização do pensamento sempre refletida por meio do binômio "inferior/superior”, explicita a compreensão não moralista da história, reconhecendo nos atores e episódios históricos, o papel que efetivamente possuíram, para, contextualizando-os, não se cair no fácil costume de se medir o passado com o metro do presente. A demonstração preconceituosa e rancorosa da atual "crise política" onde os políticos, o Presidente e seu Partido são demonstrados como mais uma tentativa frustrada de se "melhorar nossos políticos e a política" - representaria assim uma manifestação da alienação, na medida em que reconduziria nossa história a sua não absolvição, ressuscitando a ideia de que pouco valemos, e de que nossa história foi e será uma reprodução eterna de malfeitorias. A distância entre esse ponto e a ideia de que nada valemos não é muito grande, e, em tal ambiente, não será difícil vencer esse percurso por quem não continua a não assimilar a vitória do PT em 2002.

Parece razoavelmente claro que os efeitos dessa retomada de não absolvição de nossa história não oferecem qualquer esperança na direção emancipatória do homem. Uma sociedade que aceita sua própria experiência histórica sem qualquer acerto não tem motivos que a convençam a tomar parte nos processos decisórios postos à sua disposição, nem de escolher a via da política como uma alternativa válida para a busca de solução de seus problemas. Mais que isso: significa também o completo descrédito em si própria e em suas potencialidades.

Para segunda dimensão advinda da forma alienada de demonstração da "crise política", tomarei emprestada a afirmação de Marilena Chauí a respeito da característica da democracia, enquanto "forma política na qual, ao contrário de todas as outras, o conflito é considerado legítimo e necessário"29. A sociedade brasileira, por ter

\footnotetext{
${ }^{29}$ Entrevista a Juarez Guimarães, Leituras da Crise - Diálogos sobre o PT, a democracia brasileira e o socialismo. Marilena Chauí, Leonardo Boff, João Pedro Stedile, Wanderley Guilherme dos Santos entrevistados por Juarez Guimarães. 1ª edição. São Paulo: Fundação Perseu Abramo, 2006, p. 61. A
} 
compreendido sua história como "malfeitos", atribui um significado à crise de ilegitimidade, um momento que tanto não deve se repetir como não deve ser prolongado. Baseado na inexistência dos outros a entrarem em cena para absolver nossa história, como lembra Werneck Vianna, o argumento de que as crises - até antes da vitória eleitoral do PT - no Brasil somente envolviam os mesmos, é válido. Não há, então, como se pensar que um prolongamento das crises numa sociedade "tão polarizada entre a carência e o privilégio" 30 venha a ser algo benéfico, no sentido de fortalecer a democracia. Por esse motivo é que crises em governos anteriores, que contemplaram com o poder os mesmos que não contribuíram para a absolvição de nossa história, não somente deve ser debelada de imediato, como deve permanecer no âmbito do segredo, a fim de não comprometer a posição secular da balança entre carência e privilégio. Não surpreende, dessa forma, nem que a exploração da "crise" sob o governo do PT dure tanto, nem que se veja massificada em todos os meios de comunicação, repito, de forma preconceituosa e rancorosa.

O desdobramentro aqui é inevitável: uma "crise" que é imanente ao sistema democrático, e é absorvida pela institucionalidade, poderia ser tratada como um ponto positivo, a robustecer o próprio sistema em que ela se opera. A ferramenta da alienação realiza, pois, o contrário: distorce a "crise" como elemento negativo, lançando mão da não absolvição da história, abastecendo nosso preconceito contra nós mesmos, perseguindo o perverso objetivo de desdenhar de importantes passos que uma sociedade pode dar.

Não parece, pelo menos até o momento, ser visível um modo de escapar da presença do instrumento da alienação e essa presença em sociedades da periferia do

\footnotetext{
Autora completa: "A democracia não é o regime do consenso, mas do trabalho do e sobre os conflitos. Donde outra dificuldade nas sociedades de classes: como operar com os conflitos quando estes possuem a forma de contradição, e não da mera oposição? A oposição significa que o conflito se resolve sem modificação da estrutura da sociedade, mas uma contradição só se resolve com uma mudança estrutural da sociedade" (id. ib., pp. 61/62).

${ }^{30}$ CHAUÍ, Marilena. Por trás da crise está a luta de classes. Entrevista a Natalia Vianna et ali. Revista Caros Amigos, São Paulo, nº 104, novembro de 2005, p. 34.
} 
capitalismo está sujeita ao tipo de funcionamento que racionalmente colaboram para manter vivo o alerta de que a história do homem será a história de nossas tragédias, e não de nossas grandes realizações humanistas. Termino como iniciei: com Dom Quixote. Como um homem de seu tempo, não sabia ele que a caterva de feiticeiros não é, na verdade, de bruxos. Trata-se de uma plêiade de seres humanos, como dizia Guimarães Rosa, de "gente de carne e sangue" que tudo transforma, a seu gosto, para nos prejudicar, quase sempre.

\section{REFERÊNCIAS}

ADLER, Max. Kant und der Sozialismus [1904]. In: SANDKÜHLER, Hans Jörg; VEGA, Rafael de la (Hrsgg.). Marxismus und Ethik - Texte zum neukantianischen Sozialismus. Mit einer neuen Einleitung von Hans Jörg Sandkühler. Frankfurt/M.: Suhrkamp, 1974, pp. 134-156.

ARON, Raymond. O Marxismo de Marx. Trad. Jorge Bastos. São Paulo: Editora Arx, 2004.

BOTTOMORE, Tom. Dicionário do Pensamento Marxista. Rio de Janeiro: Jorge Zahar Editor, 1988.

BUCKEL, Sonja. Neo-Materialistische Rechtstheorie. In: BUCKEL, Sonja; CHRISTENSEN, Ralph; FISCHER-LESCANO, Andreas (Hrsgg.). Neue Theorien des Rechts. Stuttgart: Lucius \& Lucius, 2006.

CERVANTES, Miguel de. D. Quixote de la Mancha. Trad. Almir de Andrade e Milton Amado. v. I. São Paulo: Ediouro, 2004.

CHAUÍ, Marilena. Por trás da crise está a luta de classes. Entrevista a Natalia Vianna et ali. Revista Caros Amigos, São Paulo, no 104, novembro de 2005, pp. 30-37.

GUIMARÃES, Juarez. Leituras da Crise - Diálogos sobre o PT, a democracia brasileira e o socialismo. Marilena Chauí, Leonardo Boff, João Pedro Stedile, Wanderley Guilherme dos Santos entrevistados por Juarez Guimarães. $1^{a}$ edição. São Paulo: Fundação Perseu Abramo, 2006. 
HORKHEIMER, Max. Die gesellschaftliche Funktion der Philosophie. In: Max Horkheimer: Kritische Theorie - Eine Dokumentation. Hrsg. von Alfred Schmidt. Frankfurt/M.: S. Fischer Verlag, 1968, pp. 292-312.

LOSURDO, Domenico. Democracia e Bonapartismo. RJ/SP: Ed. UFRJ/UNESP, 2004.

MAIHOFER, Andrea. Das Recht bei Marx. 1. Auflage. Baden-Baden: Nomos Verlagsgesellschaft, 1992.

MARX, Karl. Ökonomisch-philosophische Manuskripte aus dem Jahre 1844. In: MarxEngels Werke. Ergänzungsband. Berlin: Dietz Verlag, 1968.

1989.

Manuscritos Económico-Filosóficos. Trad. Artur Morão. Lisboa: Edições 70,

MÉZÁROS, István. Marx's Theory of Alienation. New York/Evanston/San Francisco/London: Harper\&Row Publishers, 1972.

. Marx: A Teoria da Alienação. Trad. Waltensir Dutra. Rio de Janeiro: Zahar Editores, 1981.

MÜLLER, Friedrich. Entfremdung - Folgeprobleme der anthropologischen Bergründung der Staatstheorie bei Rousseau, Hegel, Marx. 2. bearbeitete und stark erweiterte Auflage. Berlin: Duncker \& Humblot, 1985.

SANTOS, Wanderley Guilherme dos. A Universalização da Democracia. In: BENEVIDES, Ma. Victoria; VANNUCHI, Paulo; KERCHE, Fábio (Orgs.). Reforma Política e Cidadania. São Paulo: Instituto Cidadania/Editora Fundação Perseu Abramo, 2003, pp. 33-43.

TEXIER, Jacques. Democracia e revolução em Marx e Engels. Trad. Duarte Pacheco Pereira. Rio de Janeiro: Ed. UFRJ, 2005. 
VIANNA, Luiz Werneck. Esquerda Brasileira e Tradição Republicana - Estudos de conjuntura sobre a era FHC-Lula. Rio de Janeiro: Editora Revan, 2006.

Submissão: 20/05/2014

Aceito para Publicação: 20/05/2014 